\title{
PENGARUH BEBAN KOMPAKSI DAN SUHU SINTERING TERHADAP DENSITAS DAN SIFAT MEKANIK ALUMINIUM WATER ATOMIZED
}

\author{
Heru Sukanto ${ }^{1}$ \\ ${ }^{1}$ Teknik Mesin - Universitas Sebelas Maret \\ herusukanto@staff.uns.ac.id
}

\section{Kata Kunci :}

green density, densifikasi, sintering, traverse rupture strength, porous

\begin{abstract}
:
The powder size used in the research were maximum of $297 \mu \mathrm{m}$ and maximum of $105 \mu$ resulted by water atomization. Both powder sizes were dry mixed by ratio of 65:35\%wt and was added by 1,25\% wt of wax. Mixing was taking a place in steel cylinder with diameter of 2" roteted at $140 \mathrm{rpm}$ for $2 \mathrm{hr}$. Green body was formed by pressing pressure of 280, 340, 400 and 435 Mpa. Sintering was conducted in argon and temperatures variation of 500, 550, 600 and $650^{\circ} \mathrm{C}$ for $2 \mathrm{hr}$.

The results show thet sintering temperature change have no significant effects on density and mechanical properties while presing pressure have dominantly effects. Traverse rupture strength, density and hardness growth with increasing pressing pressure but they will decrease with increasing sintering temperature. The best increasing of mechanical properties was occurred at temperature sintering of $500^{\circ} \mathrm{C}$ and compaction pressure of $400 \mathrm{Mpa}$.
\end{abstract}

\section{PENDAHULUAN}

Aluminium merupakan material yang sangat banyak penerapannya pada rekayasa teknik (terutama dalam bentuk paduan atau alumina) karena keunggulan sifatnya dibandingkan material lain. Beberapa keunggulan produk dari serbuk aluminium paduan, antara lain; ketahanan terhadap korosi, konduktifitas panas dan listrik yang baik, dan sifat dekoratif [The Aluminum Inc., 2001] Selain itu, produk dari serbuk aluminium paduan lebih murah dalam fabrikasi dibandingkan serbuk besi paduan. Semua keuntungan di atas dicapai dengan menggunakan aluminium dengan tingkat kemurnian yang tinggi (diatas 90\%).

Pada umumnya serbuk aluminium diproduksi dengan menggunakan metode atomisasi gas inert dan berbahan dasar ingot aluminium. Namun secara praktis serbuk aluminium dapat dibuat dengan atomisasi air dan menghasilkan aluminium dengan tingkat kemurnian rendah (mengandung oksida) dan bentuk partikelnya tidak beraturan (irreguler). Selanjutnya untuk menerapkan serbuk ini dalam rekayasa teknik memerlukan penelitian yang seksama dalam rangka menentukan sifat fisik dan sifat mekanik spesimen dari serbuk aluminium hasil atomisasi air.

Serbuk paduan aluminium yang terbuka di udara secara alami akan membentuk lapisan oksida pada permukaannya. Lapisan oksida ini sebagian besar terdiri dari alumina $\left(\mathrm{Al}_{2} \mathrm{O}_{3}\right)$ dalam fase gama yang memiliki struktur amorphous [Sato, 2000], dan berwarna gelap [Glazoff dan Novak, 1999]. Ketebalan oksida aluminium ini sekitar $0,01 \mu \mathrm{m}$ [Pozeit, 2002] dan akan bertambah dengan peningkatan suhu [Hatch, 1984]. Oksida aluminium yang terbentuk dari proses atomisasi air akan berbeda ketebalan dan struktur mikronya, mengingat kecepatan pendinginan yang sangat cepat dan kemungkinan terjadinya reaksi antara aluminium dan air [Pezoit, 2002]. Sehingga lapisan ini tidak bisa disamakan dengan alumina keramik yang memang sengaja dibuat (struktur kristal, warna putih). Keberadaan lapisan oksidayang menyelimuti setiap serbuk dan bentuk serbuk yang tidak beraturan (irreguler) akan sangat berpengaruh pada mekanisme sintering.

\section{METODE PENELITIAN Bahan}

Bahan penelitian adalah serbuk aluminium hasil atomisasi air dari bahan dasar blok mesin dengan ukuran maksimum $297 \mu$ m dan maksimum $105 \mu \mathrm{m}$ serta berbentuk irregular. Hasil uji spektrometer menunjukkan komposisi bahan dalam \%wt; yakni: $60 \% \mathrm{Al}, 15,86 \% \mathrm{Si}, 15,5 \% \mathrm{Zn} ; 2,6 \% \mathrm{Fe}$, $1,7 \% \mathrm{~Pb}, 1,7 \% \mathrm{Sn}, 0,77 \% \mathrm{Cu}$ dan $0,34 \% \mathrm{Mg}$ serta bahan paduan lainnya seperti $\mathrm{Mn}, \mathrm{Cr}$, Ni. Untuk mengurangi gesekan antara dinding cetakan dan serbuk digunakan pelumas lilin buatan Refi Chemical sebanyak $1,25 \%$ wt dengan titik lebur $99^{\circ} \mathrm{C}$ dalam furnace.

\section{Pencampuran Serbuk dan Pelumas}

Serbuk ukuran $297 \mu \mathrm{m}$ dan $105 \mu \mathrm{m}$ dengan perbandingan berat 65:35 ditambah lilin dicampur dalam silinder baja yang diputar dengan kecepatan $140 \mathrm{rpm}$ selama 2 jam (dry mixing). Maksud pencampuran serbuk ini adalah untuk menghasilkan distribusi ukuran serbuk yang merata dan untuk menghaluskan permukaan serbuk yang masih 
runcing. Tabel 1 menunjukkan data pencampuran serbuk dan pelumas.

\section{Tabel 1. Data teknis pencampuran serbuk dan} pelumas.

\begin{tabular}{|l|c|}
\hline Volume silinder $\left(\mathrm{cm}^{3}\right)$ & 257 \\
\hline Berat serbuk $297 \mu \mathrm{m}(\mathrm{gr})$ & 27,3 \\
\hline Berat serbuk $105 \mu \mathrm{m}(\mathrm{gr})$ & 14,7 \\
\hline Berat lilin $(\mathrm{gr})$ & 0,525 \\
\hline Charge ratio (berat bola besi : berat serbuk) & $2: 1$ \\
\hline Diameter bola besi $(\mathrm{mm})$ & 6,35 \\
\hline Kecepatan putaran $(\mathrm{rpm})$ & 140 \\
\hline Lama putaran (menit) & 120 \\
\hline
\end{tabular}

\section{Kompaksi dan Sintering}

Serbuk yang telah dicampur kemudian dikompaksi pada tekanan 280, 340, 400 dan $435 \mathrm{Mpa}$ dengan penekanan uni-aksial single acting. Untuk masing-masing tekanan kompaksi didesain akan menghasilkan dimensi green body $(32,5 \times 6,35 \times 12,7)$ mm [Arik dan Bagci, 2003]. Green body kemudian disinter dalam dapur listrik yang lingkungannya diisi dengan gas argon agar tidak terjadi oksidasi selama porses sintering. Suhu sintering diset pada skala 500, 550,600 dan $650^{\circ} \mathrm{C}$ dengan laju pemanasan $10^{\circ} \mathrm{C} /$ menit. Setelah mencapai suhu sintering dipertahankan selama 120 menit (2 jam) dan pendinginannya dilakukan dengan cara mematikan dapur tahanan listrik hingga mencapai suhu ruang (slow cooling)

\section{Pengujian Densitas}

Densitas spesimen diukur dengan menerapkan hukum Archimedes. Untuk spesimen yang berpori-pori memerlukan tiga kali pengukuran berat (penimbangan), yakni berat di udara bebas (W1), berat di udara bebas setelah pori-pori spesimen diisolasi (W2) dan berat di dalam air (W3). Pengisolasian pori-pori dimaksudkan agar air tidak masuk ke pori-pori ketika ditimbang di dalam air, dan ini bisa dilakukan dengan mencelupkan spesimen ke dalam minyak [2] atau dengan memberikan lapisan lilin yang sangat tipis pada permukaan spesimen [Barsoum, 1997]. Densitas spesimen dihitung dengan menerapkan rumus Archimedes yang telah dimodifikasi [2].

$$
\rho=\frac{\mathrm{W} 1 \cdot \rho_{\mathrm{a}}}{\mathrm{W} 2-\mathrm{W} 3}
$$

dengan $\rho_{\mathrm{a}}$ adalah densitas air pada suhu kamar.

\section{Pengujian Sifat Mekanik}

Traverse rupture strength (kekuatan patah melintang akibat beban bending) bahan yang getas dapat diuji dengan menggunakan metode three point bending atau four point bending [Barsoum, 1997]. Kekuatan patah melintang mengacu pada standar MPIF (Metal Powder Industries Federation) nomor 41 (Determination of Traverse Rupture Strength (TRS)) menggunakan spesimen berbentuk balok ukuran 6,35 x 12,7 x 31,7 mm. Gambar 1 menunjukkan skema pengujian TRS [Arik dan Bagci, 2003]. Data yang diperlukan untuk menghitung TRS adalah beban rupture dan defleksi spesimen.

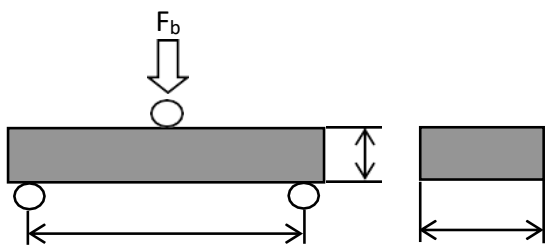

$$
\mathrm{TRS}=\frac{3 \mathrm{~F}_{\mathrm{b}} \mathrm{L}}{2 \mathrm{WT}^{2}}(\mathrm{MPa})
$$

$\mathrm{F}_{\mathrm{b}}=$ gaya tekan $(\mathrm{N})$

$\mathrm{L}=$ jarak tumpuan $(25,4 \pm 0,3 \mathrm{~mm})$

$\mathrm{T}=$ tebal specimen $(6,35 \mathrm{~mm})$

$\mathrm{W}=$ lebar spesimen $(12,7 \mathrm{~mm})$

$\mathrm{d}=$ diameter silinder penumpu $(3,1 \mathrm{~mm})$

Gambar 1. Skema pengujian kekuatan patah melintang.

Kekerasan diukur dalam skala brinell (BHN). Pengujian kekerasan dilakukan dengan beban (P) $30 \mathrm{~kg}$ dan diameter bola penekan (D) $2,5 \mathrm{~mm}$. Diameter bekas injakan (d) diamati dengan menggunakan mikroskup. Kekerasan spesimen diambil dari rata-rata lima kali pengukuran. Skala kekerasan brinell dihitung dengan rumus berikut [Shackelford, 1996]:

$$
\mathrm{BHN}=\frac{2 \mathrm{P}}{\pi \mathrm{D}\left(\mathrm{D}-\sqrt{\mathrm{D}^{2}-\mathrm{d}^{2}}\right)}
$$

\section{HASIL DAN PEMBAHASAN}

\section{Pengaruh Beban Kompaksi dan Suhu Sintering} terhadap Densitas

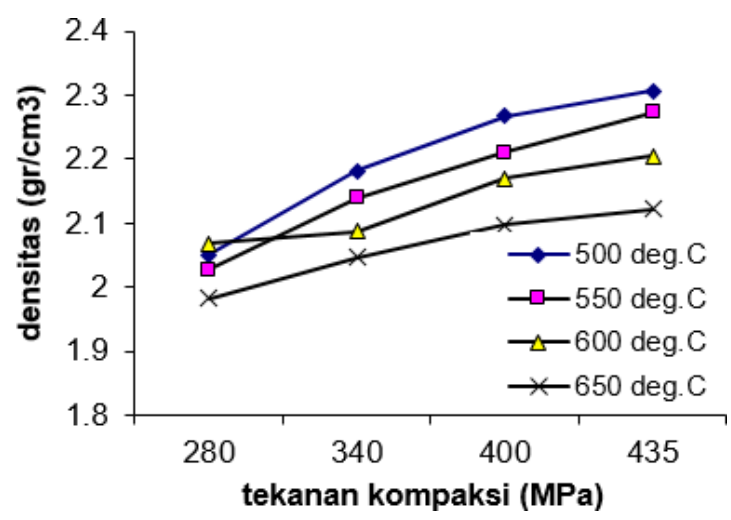

Gambar 2. Grafik pengaruh tekanan kompaksi dan suhu sintering terhadap densitas 


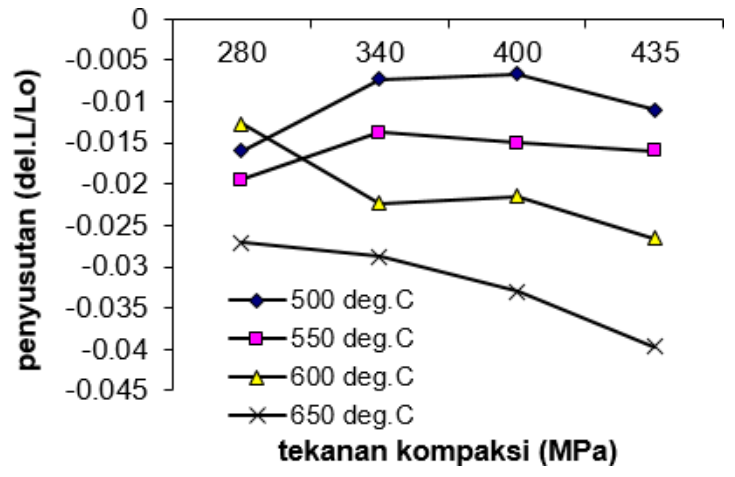

Gambar 3. Grafik hasil pengujian penyusutan (shrinkage)

Densitas spesimen berbanding langsung terhadap tekanan kompaksi, tetapi berbanding terbalik terhadap suhu sintering. Peningkatan densitas optimal terjadi pada tekanan kompaksi $400 \mathrm{Mpa}$. Penambahan beban kompaksi diatas 400 Mpa hanya akan menambah densitas dalam skala yang kecil. Seperti tampak pada ambar 2. Grafik peningkatan densitas memiliki kemiringan yang lebih besar hingga tekanan $400 \mathrm{Mpa}$, setelah melewati titik ini grafik cenderung melandai.

Kenaikan suhu sintering justru akan menurunkan densitas (gambar 2) dan menurunkan penyusutan (gambar 3). Fenomena ini disebabkan keberadaan lapisan oksida dan bentuk serbuk yang tidak beraturan. Pada sintering, ketika kenaikan suhu mencapai $450^{\circ} \mathrm{C}$, akan terjadi penambahan dimensi spesimen [Delarbre dan Krehl, 2000]. Kenaikan suhu berikutnya hingga mencapai suhu sintering, spesimen akan mengalami penyusutan karena terjadinya pertumbuhan batas kontak antar partikel (neck) dan terjadinya penyusunan ulang konfigurasi serbuk (rearrangement). Adanya oksida yang menyelimuti permukaan serbuk dengan koefisien muai panjang yang rendah akan menghambat pertumbuhan neck, sedangkan bentuk partikel serbuk yang tidak beraturan akan menghambat proses rearrangement.

Suhu sintering yang tinggi akan menghasilkan tegangan termal yang tinggi pula sehingga mampu memecah lapisan oksida. Lapisan oksida yang terbuka akan memberi jalan bagi bahan yang berada di dalamnya untuk keluar dan bereaksi dengan udara atau uap air yang terjebak di dalam pori. Reaksi ini akan meningkatkan jumlah oksida pada spesimen. Pada beban kompaksi 400 Mpa dan 435 Mpa serta suhu sintering $650^{\circ} \mathrm{C}$ akan terdapat sebagian material yang mengalir keluar dari permukaan spesimen. Hal ini bisa terjadi karena beban kompaksi yang tinggi akan mengurangijumlah udara dan uap air yang terjebak dalam pori. Sementara itu pada suhu sintering yang tinggi akan banyak bahan yang keluar dari lapisan oksida yang pecah, sehingga jumlah udara dan uap air yang berada dalam pori-pori tidak cukup untuk mengoksidasi bahan yang keluar tadi. Bahan yang bebas oksidasi tersebut akan mengalir ke permukaan dengan gaya kapiler atau menetes ke bawah dengan gaya gravitasi. Bahan yang keluar tadi akan meninggalkan oksida yang berongga seperti cangkang telur.

\section{Pengaruh Beban Kompaksi dan Suhu Sintering Pada Sifat Mekanik}

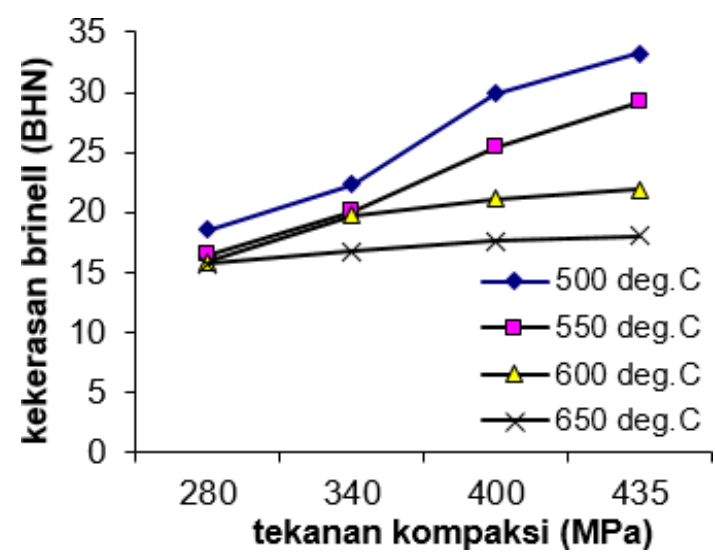

Gambar 4. Grafik pengaruh beban kompaksi dan suhu sintering terhadap kekerasan brinell.

Kekerasan brinell sangat dipengaruhi oleh beban kompaksi sedangkan kenaikan suhu sintering justru menurunkan kekerasan. Fenomena ini mirip dengan hasil pengujian densitas. Peningkatan kekerasan permukaan terbesar terjadi pada beban kompaksi $400 \mathrm{Mpa}$ dan suhu sintering $500^{\circ} \mathrm{C}(\mathrm{BHN}=$ 30) meskipun kekerasan maksimum terjadi pada beban $435 \mathrm{Mpa}(\mathrm{BHN}=33)$. Pada suhu sintering yang tinggi terjadi penurunan kekerasan yang sangat drastis. Hal ini terjadi akibat peningkatan porositas dan bergeraknya sebagian bahan yang lunak dengan titik lebur yang rendah (Al-Si atau Zn) ke permukaan.

Kekuatan patah melintang menunjukkan kecenderungan yang sedikit berbeda dibandingkan grafik densitas dan kekerasan. Pengaruh beban kompaksi sangat besar hingga tekanan $400 \mathrm{Mpa}$. Beban diatas 400 Mpa tidak akan meningkatkan TRS secara signifikan. Sementara itu, kenaikan suhu sintering hingga $600^{\circ} \mathrm{C}$ menunjukkan kecenderungan yang sama, yakni meningkat hingga tekanan $400 \mathrm{Mpa}$ kemudia cenderung konstan pada tekanan diatasnya. Penurunan TRS yang sangat drastis terjadi pada suhu sintering $650^{\circ} \mathrm{C}$. Hal ini terjadi akibat bahan yang 
keluar permukaan spesimen relatif lebih banyak, sehingga melemahkan ikatan antar serbuk. Peningkatan TRS ini terjadi karena bertambahnya jumlah oksida dan penyebarannya dalam spesimen [Pozeit, 2002].

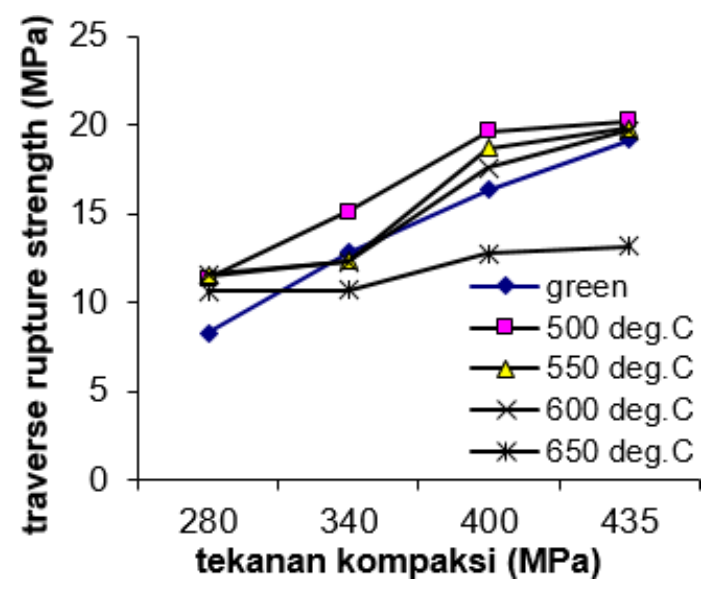

Gambar 5. Grafik pengaruh beban kompaksi dan suhu sintering terhadap TRS.

\section{KESIMPULAN}

Berdasarkan pada uji mekanik dan fisik untuk mengetahui kelayakan papan partikel limbah kemasan plastik aluminium foil dengan standar uji [7] dapat disimpulkan bahwa:

1. Peningkatan intake temperature dari $30-120^{\circ} \mathrm{C}$ yang digunakan pada pembuatan papan partikel limbah serbuk aluminium foil memiliki pengaruh terhadap penurunan sifat fisis dan mekanis yaitu nilai densitas (9.2\%), kekuatan lentur (25.03\%), modulus elastisitas (14.20\%), dan kekuatan tarik tegak lurus (15.2\%).

2. Pembuatan papan partikel limbah serbuk aluminium foil dengan variasi intake temperature $30-120^{\circ} \mathrm{C}$ menghasilkan nilai densitas dan kekuatan lentur yang memenuhi standar papan partikel [7], sementara nilai modulus elastisitas dan kekuatan tarik tegak lurus tidak memenuhi standar sebagai papan partikel [7].

\section{DAFTAR PUSTAKA}

[1] Dinas Kebersihan dan Pertamanan, "Strategi Pengelolaan Persampahan di Kota Surakarta," Indonesia, 2015.

[2] R. M. German, "Powder Metallurgy Science," The Pensylvania State University, New Jersy, 1994.

[3] B. Hendroyono, "Statistik Kementrian Lingkungan Hidup dan Kehutanan tahun 2015," Kementrian Lingkungan Hidup dan Kehutanan, Jakarta, 2016.

[4] T. M. Maloney, "Modern Particle Board and Dry Process Fibre Board Manufacturing," Miller Freeman, Inc : San Fransisco, 1993.
[5] Y. M. Massijaya, "Development of Board Made From Waste

Newspaper," Dissertation at Tokyo University ,Japan, Unpublished, 1997.

[6] E. S. Putra, "Pengaruh Tekanan Kompaksi Pressure Sintering Terhadap Ketahanan Impak dan Kekuatan Tarik Limbah Kemasan Aluminium Foil, Skripsi," Fakultas Teknik Universitas Sebelas Maret, Surakarta. 2015.

[7] B. I. Setiawan, N. Nugroho, "Pembuatan dan Uji Karakteristik Papan Partikel Serat Buah Bintaro," Skripsi, Fakultas Teknologi Pertanian Institut Pertanian Bogor, Jawa Barat, 2012.

[8] SNI 03-2105-2006, "Mutu Papan Partikel," Badan Standardisasi Nasional, Bogor, 2004.

[9] H. Sukanto, "Pengaruh Suhu Sintering Terhadap Densitas dan Kekuatan Komposit Plastik - Karet," Jurnal Ilmiah Teknik Mesin, vol. 3, no.1, pp.57-61, 2009.

[10] Suyanto, "Pengaruh Waktu Sintering Terhadap Sifat Fisik Dan Mekanik Komposit Plastik (HDPE,PET)," Skripsi Universitas Sebelas Maret, Surakarta, 2007. 